\title{
PROMINENT PLAYERS OF EM FIELD RADIATION AND EMISSION IN BPLC LINE
}

\author{
Shililiandumi Naiman ${ }^{1}$, Mussa. M. Kissaka ${ }^{2}$, Omar. F. Hamad ${ }^{3}$, Justinian Anatory ${ }^{4}$ \\ ${ }^{l}$ PhD Student, Dept. of ETE, Universtiy of Dar es Salaam, TANZANIA \\ ${ }^{2}$ Senior Lecturer, Dept. of ETE, Universtiy of Dar es Salaam, TANZANIA \\ ${ }^{3}$ Senior Lecturer, Dept. of ETE, Universtiy of Dar es Salaam, TANZANIA \\ ${ }^{4}$ Associate Professor, College of Informatics and Virtual Education, University of Dodoma, TANZANIA
}

\begin{abstract}
The paper brings to the readers the causes or factors and the extents in which they influence radiation emitted by BPLC network. The typical network topology is used to simulate those causes or factors and the paper tries to come up with theoretical agreement to what was postulated in previous studies. Some of the potential factors are analyzed and their results are discussed for the purpose of verifying the effect and, later, proposing suitable mitigation methods for each identified factor. In this paper the contributions of common mode (CM) current, line bend and the frequency to BPLC radiation are discussed. CST cable studio tools for EMC analysis are applied to simulate and confirm the influence of each factor. The results indicate that CM current due to unsymmetrical network does cause radiation and the magnitude of radiation depends on the magnitude of CM current. Also, bending the transmission line to an angle increases radiation with maximum radiation observed at 10 degree and minimum at 50 degree. The effect of frequency signal on BPLC indicates that the higher the frequency, the higher the line radiated signal with maximum radiation at $55 \mathrm{MHz}$.
\end{abstract}

Keywords: BPLC, Electromagnetic Radiation, Emission, Interferences

\section{INTRODUCTION}

The use of high frequencies for BPLC communication has become a problem since it poses a radiation and interference threat for communication equipment assigned similar frequency and to human being who are subjected to that environment. High Frequency (HF) radio services may be affected by the unwanted radiation from the new broadband PLC systems which are anticipated to radiate beyond recommended limits. For a BPLC to be widely accepted and deployed, it is necessary to ensure that, the emissions produced do not disturb other services and systems that are using the same frequency band or adjacent frequency bands.

According to European Standard, CENELEC EN 50065, BPLC has been allocated a frequency spectrum from $9 \mathrm{kHz}$ to $140 \mathrm{kHz}$ for narrow band and $1 \mathrm{MHz}$ to $30 \mathrm{MHz}$ for broadband communication with $1-15 \mathrm{MHz}$ for outdoor communication and $15-30 \mathrm{MHz}$ for indoor communication. The levels of immunity and emissions are regulated by EMC standards. The frequency range of $3 \mathrm{kHz}$ to $95 \mathrm{kHz}$ is restricted for use by electricity suppliers and $95 \mathrm{kHz}$ to 148.5 $\mathrm{kHz}$ is restricted to consumer uses. The radiation level for the band $95 \mathrm{kHz}$ to $148.5 \mathrm{kHz}$ is limited to $116 \mathrm{~dB} \mu \mathrm{V}$ for general use and for particular applications such as industrial areas which is limited to $134 \mathrm{~dB} \mu \mathrm{V}$. The frequency range 1-15 $\mathrm{MHz}$ is limited to $30 \mu \mathrm{V} / \mathrm{m}$ and $15-80 \mathrm{MHz}$ to $100 \mu \mathrm{V} / \mathrm{m}$ [1] and [2].

For human being, using BPLC services will expose them to high radiation which affects tissues and causes radiation related diseases such as brain tumor and irreversible infertility. There is evidence that the EM fields to the human body have effects if the person is exposed to it in significant amount of time beyond the recommended level. The effects are different and dependent on the frequency range [3] [4]. For human beings, the ITU has recommended a minimum level of emission for a general public exposure in the frequency range $3 \mathrm{kHz}-150 \mathrm{kHz}$ as an electric field strength of $87 \mathrm{~V} / \mathrm{m}$ and $1 \mathrm{MHz}$ to $100 \mathrm{MHz}$ as $28 \mathrm{~V} / \mathrm{m}$ and magnetic field strength of $5 \mathrm{~A} / \mathrm{m} \mathrm{[5]} \mathrm{and} \mathrm{[6].} \mathrm{The} \mathrm{effect} \mathrm{of} \mathrm{radiation}$ from BPLC for human being is analyzed by the way it reacts with our body mechanism. For the RF range the biomechanisms and related dosimetric quantities are shown in Table 1 which is caused by radiation to human body [7]; [8].

Table 1 - Metrics in exposure standards for RF range

\begin{tabular}{|c|c|c|}
\hline Frequency range & $\begin{array}{l}\text { Bio- } \\
\text { mechanism }\end{array}$ & Dosimetric quantity \\
\hline $\begin{array}{l}\text { VLF/LF (3 kHz } \\
-100 \mathrm{kHz})\end{array}$ & $\begin{array}{l}\text { Neuromuscular } \\
\text { stimulation }\end{array}$ & $\begin{array}{l}\text { Current density in } \\
\text { excitable tissues }\end{array}$ \\
\hline $\begin{array}{lr}\text { Intermediate } & \text { RF } \\
(100 \mathrm{kHz}- & 3 \\
\mathrm{GHz}) & \\
\end{array}$ & Tissue heating & $\begin{array}{l}\text { Spec.Absorption } \\
\text { Rate (SAR) in W/kg }\end{array}$ \\
\hline $\begin{array}{l}\text { Microwaves } \\
\mathrm{GHz}-300 \mathrm{GHz}\end{array}$ & $\begin{array}{l}\text { Surface } \\
\text { heating }\end{array}$ & $\begin{array}{l}\text { Power Density in } \\
\mathrm{W} / \mathrm{m} 2\end{array}$ \\
\hline
\end{tabular}

(Source: [7])

\section{RELATED WORK}

Paragraph comes content here. Paragraph comes content here. Paragraph comes content here. Paragraph comes content here. Paragraph comes content here. Paragraph 
comes content here. Paragraph comes content here. Paragraph comes content here. Paragraph comes content here. Paragraph comes content here. Paragraph comes content here. Paragraph comes content here.

From the previous works on the factor accelerating BPLC radiation, different views have been presented, [9], identifies the presence of common mode (CM) current in the network as a source of BPLC signal radiation, while [10] suggests that any discontinuity, interconnection or bent in powerline network can stand as potential source of BPLC radiation. The authors in [11] have considered BPLC as an antenna radiating when subjected to high frequency signals, describing bent or discontinuity/joints responsible to change high frequency current into EM, and vice versa. Also, [12] suggests that mismatch of impedances causes reflection and retransmission of signal in the network which mount on the signal to radiate with emission which is above the EMC recommended limit. [13], has pointed out that, lack of symmetry has high contribution to radiated signal from wire bound communication system. The summarized researchers' findings for the potential sources of radiation in BPLC due to injected communication signal in the unshielded wires are as in (i) through (vi):- (i) presence of CM current; (ii) presence of discontinuity, interconnection in the line, (iii) presence of bend in powerline; (iv) presence of impedance mismatch; (v) lack of symmetry; (vi) electromagnetic interference (EMI) from external sources; and (viii) high frequency.

\section{FACTORS FOR RADIATION EMISSION IN}

\section{BPLC LINE}

This section analyzes three of the identified factors, that is common mode current, line bend and the frequency, in relation to their contributions to BPLC radiation. It also discusses how the network system setup for simulation was implemented for each factor and the obtained results.

\subsection{Common Mode Current}

For a single phase transmission line, the current on parallel conductors is a combination of differential mode (DM) currents and common mode (CM) currents. The DM currents are the signals which are equal in magnitude, but travelling in opposite direction which is usually assumed in circuit theory. Common mode currents are the signals with equal magnitude and they have the same direction on parallel conductors which cause the electromagnetic fields to add up and hence cause radiation. CM current, also known as antenna mode current, has not been predicted or it has been considered to have negligible effect in the circuit theory, but in a high frequency it presents the BPLC radiation issues and its contribution is discussed.

Radiation in powerline due to $\mathrm{CM}$ has been discussed by many including [14], [15] and [16]. Several factors have been predicted as the main causes of CM current in the network. One of those factors is the unsymmetrical nature of a network such as unbalance line, network with unequal line length, and network with mismatched lines, nodes or load terminations. Poorly symmetrical cables convert the differential mode signal to common mode in the lines and this becomes a source of radiation [17]. The electrical unbalanced network generates common mode current which emit electromagnetic waves. The study tries to simulate the effect of CM current by designing circuit which artificially create the line unsymmetrical and, hence, CM current in the network. The level of unsymmetrical is varied and its contribution to the radiated signal is observed.

\subsubsection{Circuit Setup}

Consider the outdoor powerline channel for typical network for a single wire above earth as shown in Figure 1 with network parameters as in Table 2. The use of parasitic capacitance $C_{1}$ and $C_{2}$ connected to ground allows the creation of $\mathrm{CM}$ current by creating artificial return path through the earth. The effect of CM current is investigated using CST Microwave Studio ${ }^{\mathrm{TM}}$ radiation modeling tool for the power utility network.

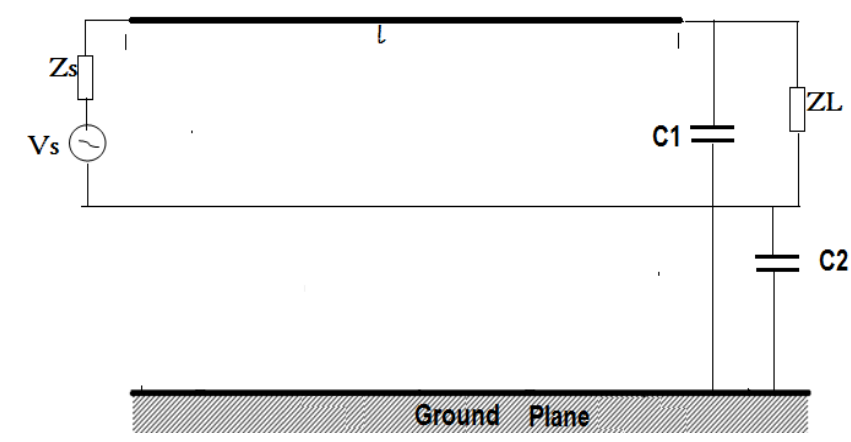

Fig- 1: The BPLC single line above ground with CM current with $\mathrm{C} 1$ and $\mathrm{C} 2$ changing

Table 2: Network parameters

\begin{tabular}{|l|l|l|}
\hline S/N & PARAMETERS & VALUES \\
\hline 1 & Resistance & $2.8 \mathrm{Ohms} / \mathrm{Kms}$ \\
\hline 2 & $\begin{array}{l}\text { (a) Length of the } \\
\text { wire } \\
\text { (b) Scaled down to }\end{array}$ & $\begin{array}{l}200 \text { meter } \\
2 \text { meter }\end{array}$ \\
\hline 3 & Height h & $12 \mathrm{~meter}$ \\
\hline 4 & Diameter of the wire & $4.5 \mathrm{~mm}$ \\
\hline 5 & Ground conductivity $\sigma_{g}$ & $5 \mathrm{mS} / \mathrm{m}$ \\
\hline 6 & Relative permittivity $\varepsilon_{r g}$ & 13 \\
\hline
\end{tabular}

The CST in Figure 2 is a setup configuration to simulate a network line with length of 2 meter and terminated at $50 \Omega$ load to examine the effect of radiation leakage when the CM current is varied. The capacitance variation are as in Table 3 for $C_{1}$ and $C_{2}$ creating a network asymmetric and CM current which is the source of radiation. 


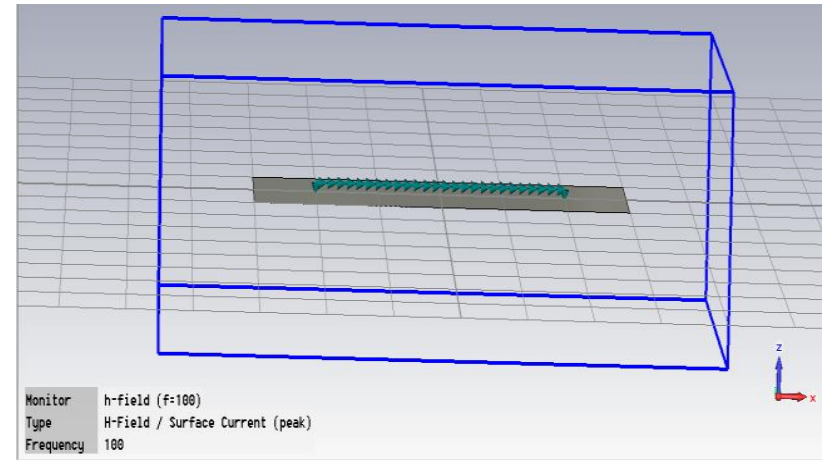

Fig -2: A line enclosed in the radiation chamber (field Monitor) to enclose the field from any external fields

Table 3: The $\mathrm{C}_{1}$ and $\mathrm{C}_{2}$ Parameters for Network CM Current

\begin{tabular}{|l|l|l|l|l|l|l|l|}
\hline $\begin{array}{l}\text { Fig. } \\
\text { No. }\end{array}$ & $\mathbf{3}$ & $\mathbf{x}$ & $\mathbf{x}$ & $\mathbf{4}$ & $\mathbf{x}$ & $\mathbf{5}$ & $\mathbf{x}$ \\
\hline $\boldsymbol{C}_{\boldsymbol{l}}(\mathbf{p F})$ & 2 & 2 & 2 & 2 & 6 & 200 & 20 \\
\hline $\boldsymbol{C}_{\boldsymbol{2}}(\mathbf{p F})$ & 2 & 11 & 6 & 101 & 2 & 2 & 20 \\
\hline
\end{tabular}

$\mathrm{x}$-un-attached figures

\subsubsection{Results of CM Simulation}

From CST Microwave Studio ${ }^{\mathrm{TM}}$ radiation modeling tool, with the simulation at frequency of $100 \mathrm{MHz}$, the magnetic field $(\mathrm{A} / \mathrm{m})$ radiation behavior for different $\mathrm{CM}$ currents equivalent to capacitances in Table 3 is as given in Figs. 3 to 4. The green color indicates the area with no radiation (fields, signals) while the red color indicates the area with maximum radiation and its value is as indicated in the bar on the right side of the each graph in the Figures 3 to 4 .

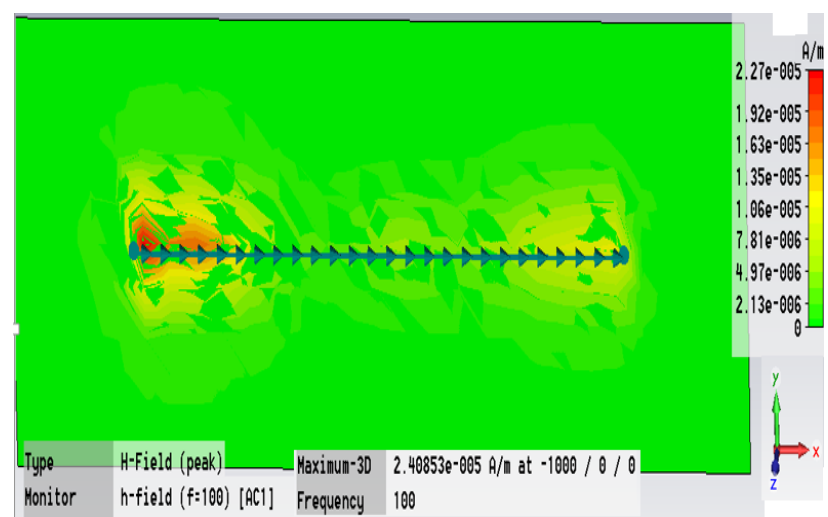

Fig-3: Magnetic Field $(\mathrm{H})$ of Maximum $2.27 \times 10^{-5} \mathrm{~A} / \mathrm{m}$ when $\mathrm{CM}$ with $\mathrm{C}_{1}=2 \mathrm{pF}$ and $\mathrm{C}_{2}=2 \mathrm{pF}$

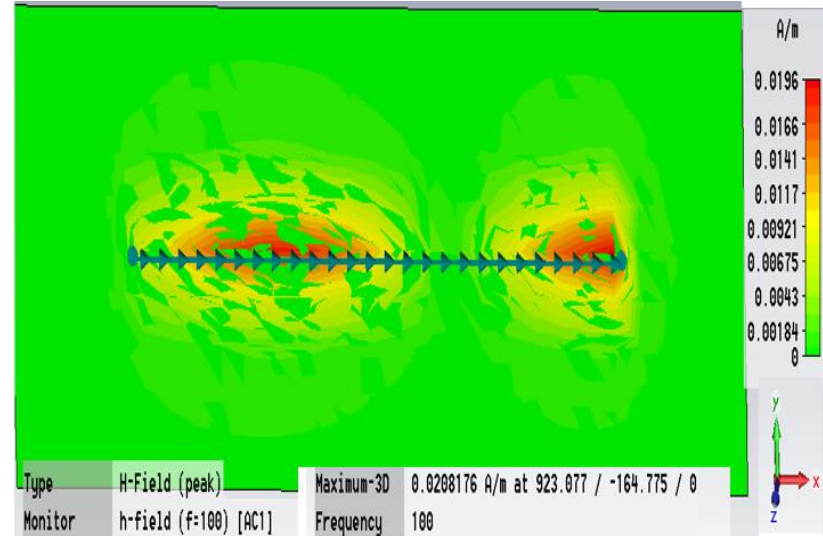

Fig- 4: Radiation signal Magnetic Field $(\mathrm{H})$ of maximum $0.0347 \mathrm{~A} / \mathrm{m}$ with $C_{l}=200 \mathrm{pF}$ and $C_{2}=2 \mathrm{pF}$

From simulation analysis, the presence of $\mathrm{CM}$ current increasese the radiation over the line as noted in Fig. 5. The radiation maginuted increases proportional with $\mathrm{CM}$ current presented by varying $C_{1}$ and $C_{2}$ to introduce mismatch in the network. The higher the mismatch the higher the radiation. Also, the radiation to the line spread along the line with highest magnitude depending on where the adds up have high values.

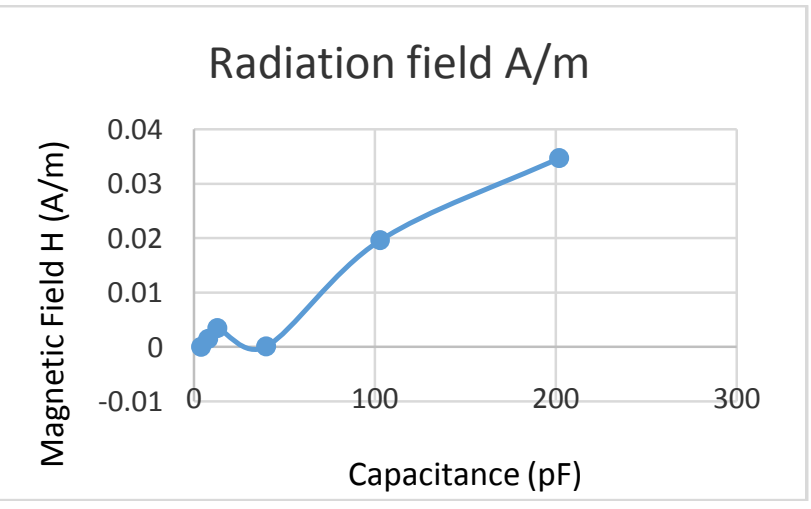

Fig-5: Magnetic Field (H) Vs CM current capacitance equivalent

\subsection{Bent in Power line}

The study suggests that the presence of bent in the BPLC contribute to radiation. The work in [12] and [18] propose that the bend of transmission line at high frequency BPLC signal contribute to high radiation. The study analyses the contribution of different line bending angle to radiation using CST.

\subsubsection{Setup and Results}

The BPLC line bended in different angles were analyzed by creating and simulating the bended line using CST.All the other line parameters were kept constant while changing the angle at each setup. The simulation was performed at the frequency of $100 \mathrm{MHz}$. The bent angles selected were $90^{\circ}$, $75^{\circ}, 50^{\circ}, 45^{\circ}, 40^{\circ}, 30^{\circ}, 10^{\circ}$ and $3^{\circ}$.The CST simulation results for particular angles were obtained and documented as in Figures 6 to 9 and the general variation trend for the bend angles and maximum radiation produced by those angles are 
summarized by Table 4 and Figure 10 . There is significant change of Magnetic field radiation as cable bend angle changes from 90 degree to 3 degree with a maximum radiation noted at 10 degree and a minimum at an angle of 50 degree. Also, a high radiated signal closer to the bend were observed as the bent line acts as an antenna changing high frequency current signal to radiated magnetic field. Hence, the higher the number of bent line in the network the higher the emitted radiation.

Table 4: Line bend angles with their respective emitted radiations

\begin{tabular}{|c|c|c|c|c|c|c|c|c|}
\hline $\begin{array}{l}\text { Angle } \\
\text { degre } \\
\text { e }\end{array}$ & $3^{\circ}$ & $10^{\circ}$ & $30^{\circ}$ & $40^{\circ}$ & $45^{\circ}$ & $50^{\circ}$ & $75^{\circ}$ & $90^{\circ}$ \\
\hline $\begin{array}{l}\text { Radia } \\
\text { tion } \\
\text { field } \\
\mathrm{A} / \mathbf{m}\end{array}$ & $\begin{array}{l}2.0 \\
6\end{array}$ & $\begin{array}{l}3.3 \\
1\end{array}$ & $\begin{array}{l}2.9 \\
7\end{array}$ & $\begin{array}{l}2.6 \\
5\end{array}$ & $\begin{array}{l}2.7 \\
8\end{array}$ & $\begin{array}{l}0.87 \\
7\end{array}$ & $\begin{array}{l}1.3 \\
3\end{array}$ & $\begin{array}{l}1.8 \\
9\end{array}$ \\
\hline
\end{tabular}

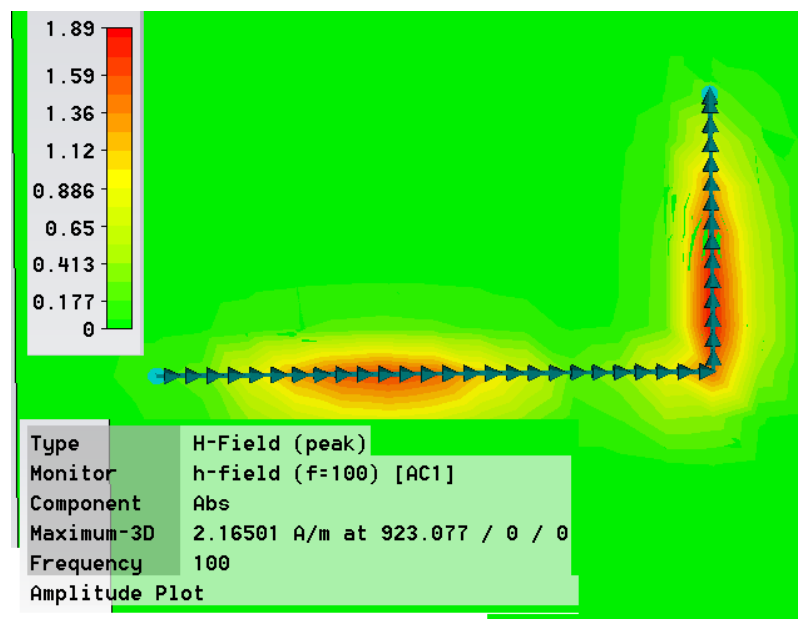

Fig-6: Magnetic Field at the line with bend angle of $90^{\circ}-$ maximum $\mathrm{H}(1.89 \mathrm{~A} / \mathrm{m})$

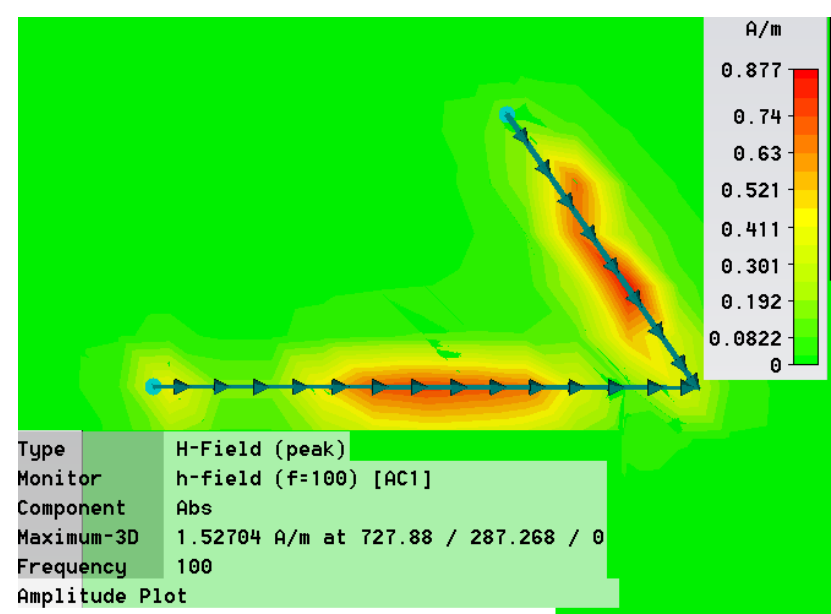

Fig-7: The $\mathrm{H}$ Field at the line bend angle of $50^{\circ}$ at $100 \mathrm{MHz}$, the maximum $\mathrm{H}(0.877 \mathrm{~A} / \mathrm{m})$

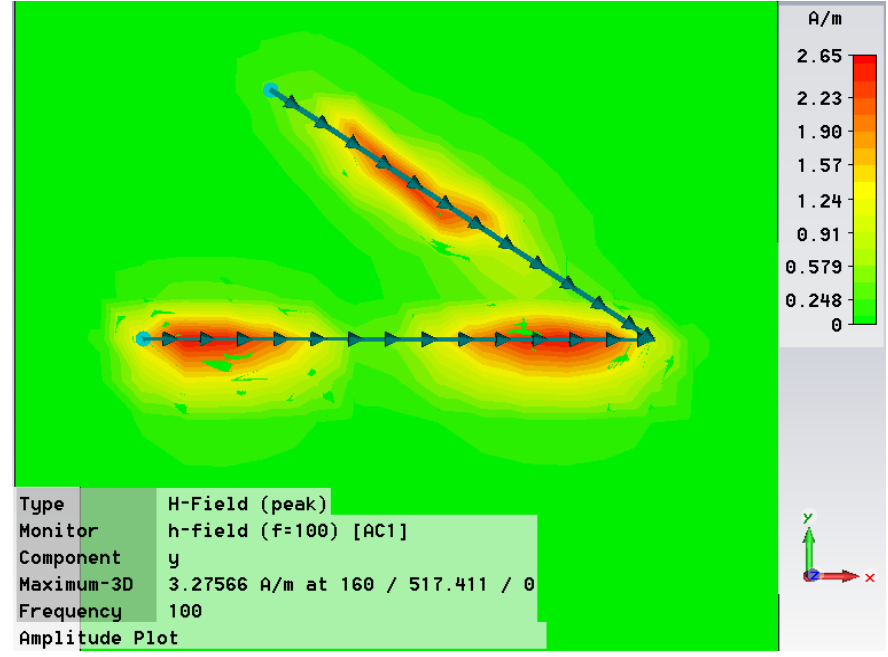

Fig-8: The H Field at the line bend angle of $40^{\circ}$ - maximum $\mathrm{H}(2.65 \mathrm{~A} / \mathrm{m})$

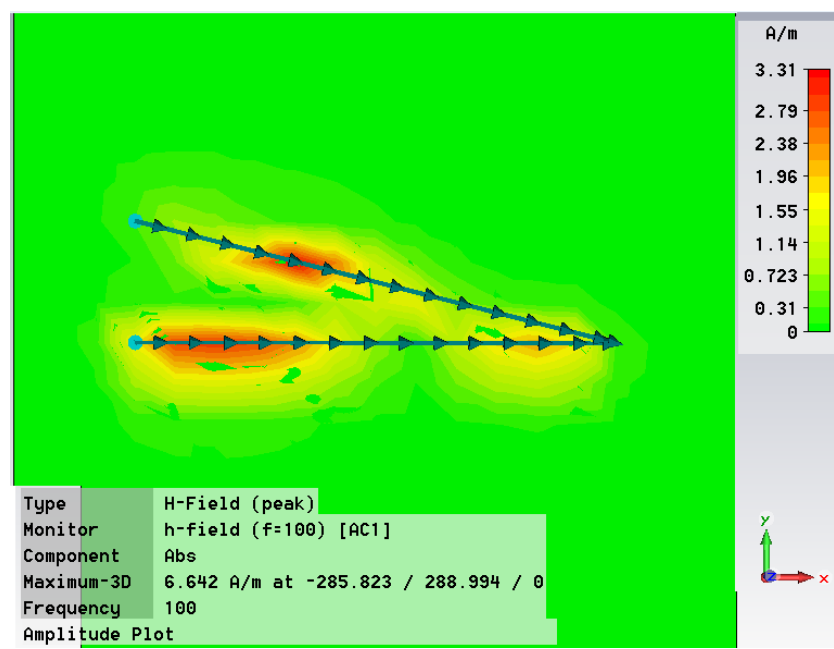

Fig- 9: The $\mathrm{H}$ Field at the line bend angle of $10^{\circ}$ - maximum $\mathrm{H}(3.31 \mathrm{~A} / \mathrm{m})$

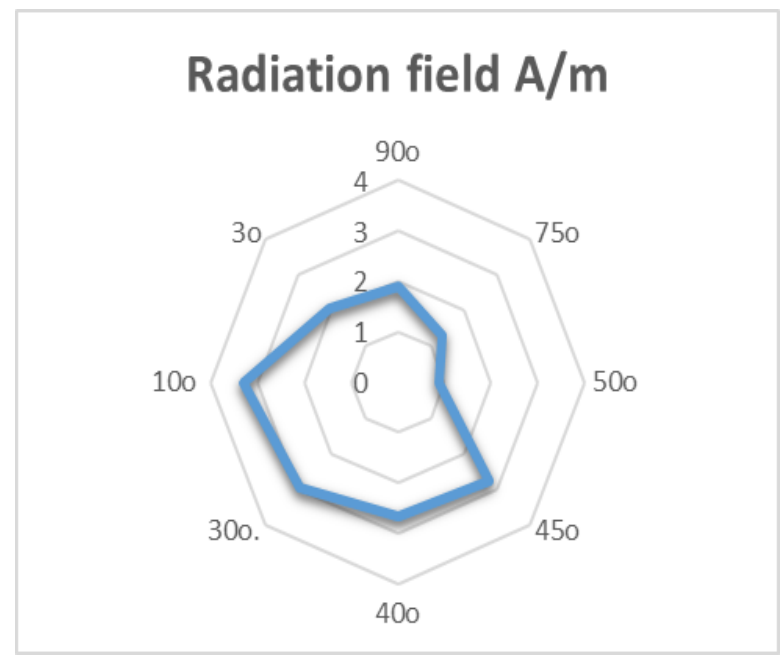

Fig-10: The H- Field radiation variation with respective bend angle between 30 to $90 \mathrm{o}$ at $100 \mathrm{MHz}$ 


\subsection{Variation of Frequency in Unshielded Wires}

Injected high frequency signals along the unshielded power transmission line emit radiation. The injected BPLC signals are designed to operate at a frequency band of $1-100 \mathrm{MHz}$ while unshielded transmission line has been designed to operate at $50 \mathrm{~Hz}$. At these $\mathrm{MHz}$ frequencies, the unshielded cable tends to behave like long antennas radiating unwanted signal. This section presents the contribution of high frequency signals to BPLC radiation by setting up a BPLC circuit and analyzing its contribution using CST tool.

\subsubsection{Setup and Results}

The circuit to analyse the radiation contribution of high frequency to BPLC radiation using CST Microwave studio was setup as in Fig 11, setting all other parameters fixed and changing the applied frequency only. The frequency was varied from $5 \mathrm{MHz}$ to $100 \mathrm{MHz}$ with high radiation observed at the interconnection.

From CST simulation results for different frequencies, the values of $\mathrm{H}$ field for respective frequencies were obtained and plotted in Figure 12. The results, generally, show that there is an overall increase in signal radiation over the line as the frequency increases and the effect spreads all over the line at high frequency with a maximum value observed at 55 $\mathrm{MHz}$.

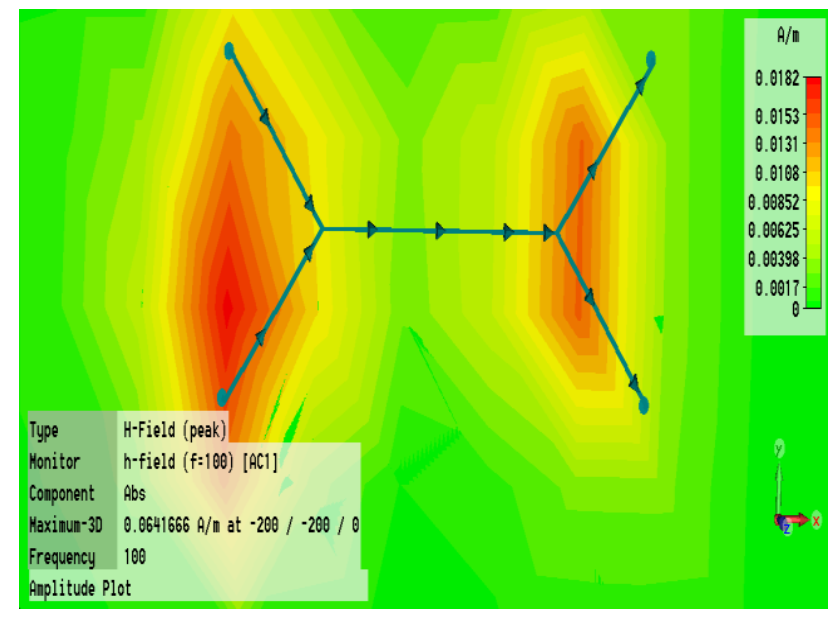

Fig-11: Power line network radiation spread across intersection of line at frequency of $80 \mathrm{MHz}$

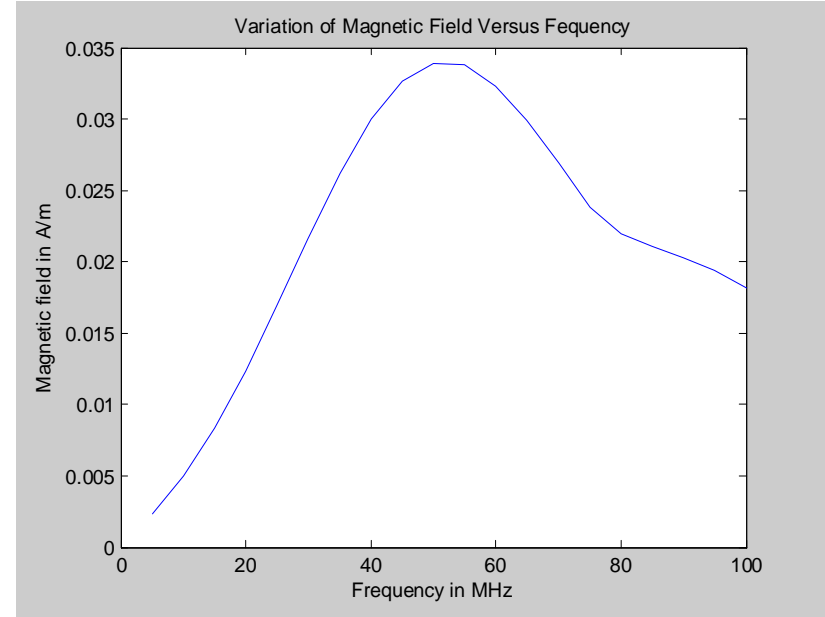

Fig- 12: The Variation of BPLC Magnetic $(\mathrm{H})$ field radiation with Frequency

\section{CONCLUSIONS}

From the CST results, it has been revealed that common mode current, line bend and high frequencies significantly do contribute to BPLC radiation. The model to characterize these radiations for proper radiation prediction has to be developed. These models can serve as radiation prediction tools and can be used to formulate the radiation mitigation mechanisms.

\section{REFERENCES}

[1] H. Ferreira, H. Grové, O. Hooijen, and A. H. Vinck, "Power line communication", Workshop on Communication over Powerline, Essen German, 2001, pp. 706-716.

[2] M. Ianoz, "Electromagnetic Effects due to PLC and Work Progress in Different Standardization," Avenue de Lavaux 281009 Pully, pp. 1-20, .2002

[3] Z. Wang, "Electromagnetic Field Interaction with Biological Tissues and Cells," 2009

[4] T. Williams, "The Health Effects of Electromagnetic Radiation," IEEE Colloquium on Electromagnetic Compatibility in Heavy Power Installations, 1999, vol. 11, pp. 1-6.

[5] B. Yazdani, J. Wegert, H. Brown, P. and Honary, "Effect of powerline transmissions on HF channels," IEEE Colloquium. Frequency Selection and Management Techniques for HF Communications, vol. 1999, pp. 1-7, 1999

[6] E. Teixeira and F. Marques, "Modeling and performance analysis of PLC channels with external interference in outdoor and indoor environments," IEEE Trans. Electromagn. Compat, pp. 222-227, 2008

[7] V. Roje, "Wire antenna theory applied to the assessment of the radiation hazard in the vicinity of the GSM base stations," Serbian J. Electr. Eng., vol. 1, no. 1, pp. 15-26, 2003

[8] W. D. J. Anders Ahlbom, James Bridges, "Scientific Committee on Emerging and Newly Identified Health 
Risks SCENIHR Possible effects of Electromagnetic Fields ( EMF ) on Human Health," 2007

[9] T. S. Pang, P. L. So, S. Member, K. Y. See, and A. Kamarul, "Modeling and Analysis of Common-Mode Current Propagation in Broadband Power-Line Communication Networks," vol. 23, no. 1, pp. 171179, 2008

[10] W. Zhang, Ming \& Lauber, "Evaluation of the Interference Potential of PLC Systems," IEEE Int. Symp. Power Line Commun. Its Appl., pp. 296-301, 2006

[11] M. Chaaban, G. Bousaleh, R. H. Chehade, A. Ismail, K. El, K. and Drissi, and C. Pasquier, "Reduction of Power Field Radiation for PLC Applications," in International Conference on Advances in Computational Tools for Engineering Applications, ACTEA, 2009, pp. 422-426

[12] S. Lee and M. Hayakawa, "A study on the Radiation Loss from a Bent TransmissionLine," IEEE Trans. Electromagn. compact. vol. 43, no. 4, pp. 618-621, 2001

[13] S. Battermann and H. Garbe, "Influence of PLC Transmission on the Sensitivity of a Short-Wave," International Symposium on Power Line Communications and Its Applications, pp. 224-227, 2005

[14] S. Tsuzuki, M. Yoshida, and Y. Yamada, "Power-line channel modeling for common-mode signal transmission/suppression," Int. Symp. Power Line Commun. It's Appl. 2005, pp. 210-214, 2005

[15] P. Favre, C. Candolfi, M. Schneider, M. Rubinstein, P. Krähenbuehl, and A. Vukicevic, "Common mode current and radiations mechanisms in PLC networks," pp. 348-354, 2007

[16] M. Kitagawa, "LCL and Common Mode Current at the Outlet Do Not Tell the Common Mode Current Generated at the Remote Unbalanced Element on the Power-line," 2009 20th Int. Zurich Symp. Electromagn. Compact, no. 3, pp. 1-4, Jan. 2009

[17] P. Favre, Patrick, Candolfi, Cedric and Krahenbuehl, "Radiation and disturbance mitigation in PLC networks," Proceedings, 20th, Int. Zurich Symposium on EMC, 2009, pp. 5-8

[18] S. Lee and M. Hayakawa, "Characteristics of Unexpected Radiation from Bent Transmission Lines," in URSI, 2002, no. 1, pp. 1-4 